This is an author produced version of a paper published in Ergonomics. This paper has been peer-reviewed and is proof-corrected, but does not include the journal pagination.

Citation for the published paper:

Lindroos, O. (2009) Relationships between observed and perceived deviations from normative work procedures. Ergonomics.

Volume: 52 Number: 12, pp 1487-1500.

http://dx.doi.org/10.1080/00140130903197461

Access to the published version may require journal subscription.

Published with permission from: Taylor \& Francis

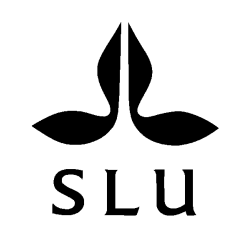

Epsilon Open Archive http://epsilon.slu.se 


\title{
Relationships between observed and perceived deviations from normative work procedures
}

\author{
Ola Lindroos \\ Dept of Forest Resource Management, Swedish University of Agricultural Sciences, Sweden \\ Published 2009 in Ergonomics 52(12), 1487-1500. \\ The original publication is available at www.tandfonline.com.

\begin{abstract}
Deviations from anticipated courses of events are often associated with accidents, while the effects of deviations that decrease productivity but do not obviously lead to human injury are less clear. A systemic approach to production and safety is introduced, and it is proposed that production deviations have effects that may lead to safety violations and personal injury. In addition, the relationship between observed and perceived production deviations from 12 senior (60-79 years old) males' routine work using three firewood processing machines is analysed. For simple machine work, perceived deviations were positively related to observed deviations per work cycle and inversely correlated to the perception of work efficiency. For more complex machine work it was more difficult to match observers' and operators' perceptions of deviations. Despite challenges in the production deviation concept, this approach offers a holistic understanding of the performance of human-machine-environment systems and complements assessments of deviations from safe working practice.
\end{abstract}

Keywords: Production deviations, perception, human error, equipment safety, firewood.

\section{Introduction}

Deviations are defined here as system values that fall outside an accepted norm (Kjellén 1984), i.e. cases in which anticipated courses of events are not followed, and they have widely acknowledged influence on accident events at both individual (e.g. Elvik 2006; Hale and Glendon 1987; Reason 1990) and organisational levels (e.g. Rasmussen 1997; Reason 1995). Consequently, deviation is a key concept in several theoretical frameworks that have been constructed to explain and prevent accidents (e.g. Hale and Glendon 1987; Hale et al. 1997; Harms-Ringdahl 2009; Hollnagel 2004; Johnson 1975; Kjellén 1984). Other strands of ergonomic research have focussed on normative human activity in order to improve the function of the humanmachine-environment (HME) systems (e.g. Baber and Stanton 1994, 1996; Karwowski 1991). The deviation concept has proved to be useful in occupational health and safety research (Kjellén and Hovden 1993), and in product usability research (Baber and Stanton 1994; McClelland 1998).

Research in occupational safety tends to focus on the causes to which accidents are attributed and often involves assessment of the impact of inappropriate human actions (Dekker 2002). The findings of such research often prompts the introduction of safety standards, aiming to influence human actions in ways that prevent accidents and improve the general safety of systems and/or meet specific safety targets (Nuutinen 2005). Hence, the focus is on analysing the deviation in the initial phase of an accident sequence, essentially addressing the question 'What deviated?'. However, if one instead asks 'Why did it deviate?', the underlying causes that drive the deviating behaviour can be identified (Dekker 2002). In order to encompass the factors that influence deviations, and ultimately accidents, a wider spectrum of issues must be assessed (e.g. perceptions of goal fulfilment). To a certain extent, this is done in product development and usability assessments. However, when a product has entered the market place, ergonomic research has tended to focus on machine design in order to reduce the probability of human error (e.g. Norman 2002; Stanton and Stevenage 1998).

Although production deviations have previously been studied from either a safety or performance perspective, the two perspectives have seldom been jointly applied. Deviations in production processes are typically considered in risk assessments, as they in comparison to accidents provide greater data quantities (Kjellén 1984). However, only deviations clearly related to accident sequences (i.e. recognised 
deviations from safe working procedures) are considered, while deviations that result in reduced productivity are largely ignored. In product usability studies, production deviations are assessed, but the deviations considered are mainly restricted to human errors (McClelland 1998), despite the possibility of machine malfunction. Methods for integrating assessment of both the usability of the product and the human actions have been advocated and provided (Baber and Stanton 1994), but the relationship between machine malfunction and human error has not been studied to any significant degree. Consequently, assessments of human-machine performance have hitherto almost exclusively focussed on either productivity or human safety ( $c f$. Nuutinen 2005).

This paper introduces a systemic approach for assessing manufacturing production and safety, and proposes that production deviations are likely to influence behaviour in ways that might lead to personal injury (Figure 1). The occurrence of a deviation from a prescribed production procedure, which subsequently causes an accident, is founded on an assumed causal relationship between actual and perceived deviations, and/or the resulting decreased work efficiency and behavioural change.

To the author's knowledge, the relationship between occurrence and perception of deviations from normative production processes have seldom been studied. In contrast, other aspects of the proposed approach have been intensively studied. Humans are known to interact with their work environment in order to attain specific goals, and numerous theories have been proposed regarding these interactions and their possible implications (e.g. Gibson 1986; GieloPerczak and Karwowski 2003; Heider 1958; Kaplan 1983). Notably, such interactions may reduce safety margins and provoke departures from safe working practices (Battmann and Klumb 1993; Hollnagel 2004; Lawton 1998; Phipps et al. 2008). Hence, production deviations and associated reductions in efficiency may provide sufficient stimulus to trigger undesirable behavioural changes. Errors occur in most systems, i.e. a certain level of deviation is inevitable (Karwowski 1991; Perrow 1984), but the extent of deviation (stimulus) required to be categorized as a problem and subsequently influence individual behaviour is affected by the operator's goals, which in turn are influenced by factors such as internal and external demands, and the operator's prior experience of similar situations (Cowan 1986; Klein et al. 2005; Lawton 1998; Phipps et al. 2008). According to the concept of self-regulation (Higgins 1997; Higgins 2000) in pursuit of a work goal, an individual will apply one of two main focuses: either a promotion focus (what can be won?) which indicates sensitiveness to production processes, or a prevention focus (what can be lost?) for which avoidance of undesired outcome is emphasised, as e.g. malfunctioning equipment (Chernev 2004). It can thus be argued that production deviations imply behavioural changes, irrespective of operators' goal orientations.

In highly repetitive work situations, deviations are likely to be definable and observable. Moreover, such errors are likely to significantly influence an individual worker's perception of work efficiency. In situations where workers can influence their own work methods, they are likely to be more efficiency focussed and thus more observant and intolerant of production deviations. The study presented here focuses on deviations in processing firewood (defined here as solid wood, mainly from the tree trunk) for domestic use in Sweden, for the following reasons. The commonly performed work is highly repetitive, often managed by an individual working autonomously (Lindroos et al. 2008), and firewood processing machines are relatively simple to operate. In addition, safety standards were introduced after the machine development, but there are high frequencies of accidents and indications of frequent safety violations during this type of work in Sweden (Lindroos et al. 2008). Hence, firewood processing appears to be a highly appropriate work model for investigations of the causes and effects of production deviations.

In Sweden, persons conducting this type of work have been found to be predominantly older men (more than 50, and sometimes more than 80 years old) (Lindroos et al. 2008), and the activity has been found to have high recreational and work satisfaction values for elder people (Carlsson 2003). In small-scale firewood processing activities, the HME components that constitute causes for deviations from normal production processes can be related to raw material, machine performance and operator behaviour, while perceived deviations are influenced by factors such as internal and external demands and experience of similar work.

In Sweden, during 2002 at least 13200 new firewood cutters, splitters and processors were sold (Lindroos et al. 2005). Since 1995 all firewood machinery has had to comply with European standards (European Committee for Standardization 1999, 2002, 2003, 2004), which prescribe (inter alia) that the machines should be used by a single operator and they should have safety features such as the wedge splitters' two-handed controls. Provided that operators comply with these stipulations, the standards are designed to ensure operator safety. However, more than half of the accidents related to firewood production occur when work is undertaken 
by more than one person, and hand accidents appear to be numerous and severe (Lindroos et al. 2008). The use of old or home-made machines, which might not comply with current safety standards, is probably the cause of some, but not all, of the accidents that occur. Other contributing factors include the deliberate avoidance of, or ignorance about, safety standards, which would probably be identified in traditional accident analyses. However, given the principle of local rationality, i.e. that what people do makes sense at the time (Simon 1970), the key issue is not the fact that operators did not comply with the safety standards, but the reasons why they did not comply (Battmann and Klumb 1993; Phipps et al. 2008). In order to elucidate these reasons the error-inducing conditions present in the working environment must be identified (Dekker 2002). Since the perception of insufficient work efficiency is a plausible explanation for noncompliance, analyses of production deviations could be an important component of such research.

The systemic approach to productivity and safety proposed here is based on the assumption that both human- and machine-caused production deviations may be indirectly related to the occurrence of accidents, since deviations that cause a reduction in productivity might provoke changes in work behaviour. Hence, it is suggested that the number of individuals who employ risky behaviour could be reduced if production deviations could be minimized. Improved knowledge of the relationships involved could contribute to more thorough assessments of the productivity and safety of both new and existing machines, and facilitate evaluations of the effects of product specifications (e.g. safety standards) on potentially accident-causing deviations and behaviour. This paper critically scrutinise the suggested approach by evaluations of relationships between actual production deviations and the operators' perceptions of deviations and work efficiency.

\section{Material and Methods}

Self-paced firewood processing with three machines (a blade saw, a hydraulic wedge splitter and a firewood processor, hereafter called cutter, splitter and processor, respectively) was studied in an experimental design that allowed controlled observations of work performance in a natural setting. Wood of two classes was processed in tests with each machine, resulting in six treatments. Each study day was divided into three 90-minute shifts, and each individual operator worked on all treatments over two days. Between each working shift, 95 (standard deviation (SD) 17) min of rest with sustenance was taken, and the operators had at least one day's rest between workdays. In total, 12 operators were randomly assigned to treatment orders and work days and were asked not to discuss the study with each other. Experimental settings relevant for the current paper are presented here, but more comprehensive details and productivity results are presented in Lindroos (2008).

The cutter divided logs into chunks, while the splitter split chunks into billets. Hence, the two steps in the processing were conducted separately in both time and space. The processor had identical main components and capacity to the cutter and splitter, but performed both processing steps, albeit at separate times. During operation, all machines were used conjunctly with a conveyor belt system, which removed the finished products. All firewood machines and conveyors were electrically powered and manufactured by Lennartsfors AB (Årjäng, Sweden) (cutter, splitter, processor and conveyor belt models: $114,60 \mathrm{E}, 2000 \mathrm{E}$ and 108, respectively).

The 12 operators were selected through snowball sampling to represent a common, homogeneous class of firewood processing persons who were male, 60-79 years old and had several years experience of processing solid firewood volumes of between 10 to $50 \mathrm{~m}^{3}$ and of using a circular saw cutter and hydraulic splitter. Potential candidates were excluded if they smoked, had restraining physical conditions, had processed firewood volumes exceeding $50 \mathrm{~m}^{3}$ per year and experience of work with a firewood processor. Their mean (SD, range) age, height and mass (the latter with clothes and shoes) was 69.6 years $(5.5,60-79), 1.73 \mathrm{~m}(0.06,1.65$ $1.85)$ and $79.9 \mathrm{~kg}(5.2,70.9-90.2)$, respectively. Prior to the study, operators were asked about their level of motivation for their routine firewood processing, which yielded a high mean score: 7.1 (SD 1.6) on a 10 -grade scale, where 10 was the highest possible motivation for the work.

The study was conducted in December 2005 in an open-sided building in Vindeln, Northern Sweden $\left(64^{\circ} 12 \mathrm{~N}, 19^{\circ} 43 \mathrm{E}\right)$. The study was conducted on $91.9 \mathrm{~m}^{3}$ solid birch (Betula $\mathrm{sp}$.) wood. The log's $(n=2199)$ diameter on bark at the top end was $>5$ $\mathrm{cm}$, their lengths were between 2.0 and $6.0 \mathrm{~m}$, and the width of crooks did not exceed the log's largest diameter by more than $30 \mathrm{~cm}$. The logs were sorted into three groups according to their root end diameter on bark (7.0-12.9, 13.0-17.9 and 18.0-30.0 cm), and those in the smallest and largest diameter group were pooled in a ratio of 5:1 to constitute Wood Class 2, while those in the medium root diameter group constituted Wood Class 1 . The logs had a raw density of $851 \mathrm{~kg} \mathrm{~m}^{-3}$ (SD 41), a moisture content of $41.7 \%$ (SD 2.2) and were frozen during the study. 
The root end of the logs was always oriented towards the machine and processed first.

Prior to each work shift, operators were told to work at their own pace and were given instructions regarding safety and standardised working procedures (see Table 1, to process one log or chunk at a time and to move a new supply of logs or chunks into a demarcated two-metre area in close proximity to the machine when that area was empty). The chunk length was set to $30 \mathrm{~cm}$ and all wood chunks were to be split, with the maximum acceptable size of billets corresponding to a quarter of a cylinder with a diameter of $20 \mathrm{~cm}\left(0.0047 \mathrm{~m}^{3}\right)$. Only billets larger than the maximum size were to be re-split. The operators had a maximum-sized billet, kept within sight during work shifts, to act as a guide for quality purposes. Operators worked under active supervision for 5-10 min prior to each shift. During work shifts, an observing researcher was located approximately $4 \mathrm{~m}$ diagonally behind the operator. The researcher corrected unsafe behaviour, violations of any standardised work routines and, if necessary, helped to correct any machine malfunction. Excluding these actions the researcher did not intervene during the operators' work. Two researchers were employed for this assessment, each assigned to the same operators throughout the study. The researchers' assessments were harmonized by joint studies of live and video filmed work prior to the study and discussions during the study. In order to harmonize data comparisons between machines, work cycles were defined as elements b-d, a-c and b-e in Table 1 for cutter, splitter and processor work, respectively.

The study only addressed skill-based errors and actively excluded error types including problemsolving (c.f. Rasmussen 1983; Reason 1990). This limitation was imposed to assess deviations that can be expected (yet unwanted) in the normal work procedure, but not severe deviations, such as machine breakdowns. Hence, machine breakdowns and various kinds of stoppages due to specific operator needs were not defined as deviations. Stoppages, for various reasons, accounted for $0.9 \%$ of the total study time (109 h). Clearly dangerous procedural deficiencies, e.g. violations of safety regulations, were immediately corrected during the study, in order to ensure the operator's safety.

Deviations from normal work procedures were identified through interviews with experienced workers and from observations in pilot studies with the machines. Recorded deviations were structured into the categories of extra work and disturbances (cf. Tables 1 and 2). Extra work comprised the additional processing of particularly large logs (i.e. where there was a miss-match between equipment and raw material) and was divided into subcategories of re-cuts and re-splits. Observed disturbances were divided into sub-categories of either external or human disturbances. External disturbances were those considered to be caused by problems with the machinery or the wood, while human disturbances were those considered to be caused by the operator (cf. Table 2). The term human error is avoided, since the study only addressed skill-based errors and actively excluded error types including problem-solving (cf. Rasmussen 1983; Reason 1990).

During observed work periods, the number of deviations that occurred was counted, together with the number of work cycles. Each re-splitting of a billet was counted, so the correct splitting of a large round wood chunk could be succeeded by, for example, four re-splits. The unsuccessful splitting of a chunk of wood of appropriate diameter $(<20 \mathrm{~cm})$ was counted as an external disturbance.

In order to match operators' perceptions of deviations, observed deviations were only counted if they were corrected by the operator. For instance, the resplitting of a billet that was too large was counted as a deviation (re-split), but if such a billet not was further processed it was not counted as a deviation. In addition, deviations that were immediately corrected were not counted if they did not result in a cessation in the work process. For instance, if the processor's splitting actuator was not pushed hard enough to actuate splitting and the operator continued to cut off another chunk of the log without the first being split, this was counted as a human disturbance. On the other hand, no deviation was recorded if the operator immediately noticed the insufficient push and corrected the error without commencing any other work operation. When many deviations occurred simultaneously, the category with the largest number was recorded as one deviation. On a similar basis, human disturbance was prioritised over external disturbance, which was prioritised over re-splits and re-cuts. For instance, if the operator forgot to return the splitter's piston in the process of returning the chunk for another try after a failed splitting attempt, the sequence was recorded as one human disturbance.

The recorded deviations were quantified in relation to performed work cycles or work time. This conforms to safety research methodology (e.g. probabilistic risk assessment and human reliability assessments), where deviations are treated in terms of the probability of occurrence. In terms of such methodology, however, the assessment was incomplete, since possible inappropriate responses (e.g. unsafe responses) to the deviations were not allowed. In usability research terms the methodology 
used is similar to human error identification, but is more comprehensive in its error uptake since it also includes machine malfunctions. The relationship between deviations and final productivity $\left(\mathrm{m}^{3}\right.$ of processed wood) is described in Lindroos (2008).

Directly after each shift the operators were individually interviewed about their work. The same questions were asked in each interview, and the questions had been discussed before each operator's first work shift. Operators reported their perceived level of work disruption (i.e. deviations), physical exertion, work efficiency, motivation and risks during the normal work using a Borg CR100 scale with instructions adapted from Borg (1998). Borg's Category-Rate scales are suitable for measuring the intensity of most types of experiences (Borg 1998) and the CR100 scale is a Category-Rate scale which ranges from 0 to 100 centiMax (cM) units, with descriptive adjectives that correspond to certain numbers on the scale (Borg and Borg 2002). The scale's main anchor is at the number 100 (described as "Maximal"), which represents the strongest previously experienced intensities. However, the scale allows operators to report higher values than 100 . Alterations to the CR100 scale were made in terms of excluding cue triangles and in translating the anchor terms to Swedish. With regard to the latter, the wording was adapted to the questions where necessary and as appropriate. Questions were also asked in the interviews concerning perceived causes of deviations, desired changes to the work, perceived risks and whether the operator would like to work in a similar manner at home.

During the study, the operators were not informed that their work was being studied in terms of production deviations, to ensure that normal working conditions prevailed and to avoid drawing attention to the deviation aspect of the study.

The method used to analyze effects of treatments was analysis of variance (ANOVA), based on the model:

$y_{i j k}=\mu+\alpha_{i}+\beta_{j}+(\alpha \beta)_{i j}+c_{k}+(\alpha c)_{i k}+(\beta c)_{j k}+e_{i j k}$

where $y_{i j k}$ is the response variable, $\mu$ is the grand mean, $\alpha_{i}$ is the fixed effect of machine, $\beta_{j}$ is the fixed effect of wood class, $c_{k}$ is the random effect of operator and $e_{i j k}$ is the random error. The model also contains a fixed interaction effect $(\alpha \beta)_{i j}$ and two random interaction effects $(\alpha c)_{k m}$ and $(\beta c)_{j k}$. Where there were no significant interaction effects with operator, those interaction effects were removed from the model to improve the otherwise low degrees of freedom in the analysis of operator as main effect. The full and modified models were referred to as the full ANOVA and truncated ANOVA, re- spectively. A general linear model (GLM) was used for analyzing the ANOVA models (SPSS 12.0, SPSS Inc.). Pairwise differences were analysed with Tukey's HSD test in cases of homogeneous variances (Laverne statistic) and otherwise with Dunnet's $\mathrm{C}$ test. Binomial data were arcsine-transformed according to Freeman and Tukey in order to allow pairwise analyses of differences (Zar 1999). Variable relationships were established through simple linear regression analysis. The critical significance level was set to $5 \%$.

\section{Results}

The deviations recorded by researchers during the work shifts are hereafter referred to as observed deviations (in absolute numbers, or rates per cycle or work shift), while the deviations perceived by the operators and reported on the CR-100 scale are presented in terms of perceived deviation levels.

\subsection{Observed deviations}

Both the number of performed work cycles and the number of observed deviations to normal work were found to vary between machines, wood classes and operators. The number of observed deviations correlated significantly with the number of performed work cycles: positively for work with the cutter $(\mathrm{p}=$ $0.001)$, but negatively for work with the splitter $(\mathrm{p}=0.043)$ and processor $(\mathrm{p}=0.023)$ (Figure 2). Therefore, unless otherwise stated, the rate of observed deviations per work cycle was used as the measure of deviation frequency rather than the total number of observed deviations per work shift.

There were significant differences in observed deviations per work cycle between machines (full ANOVA, $\mathrm{p}<0.001$ ), but no significant effects of wood class, operator or any of the pairwise interactions of the three factors (full ANOVA, $\mathrm{p} \geq 0.211$ ). According to the truncated ANOVA, both machine and operator had significant main effects $(\mathrm{p} \leq 0.035)$, but neither wood class nor the interaction between machine type and wood class had significant effects ( $\mathrm{p} \geq 0.376$ ).

Cutter work resulted in fewer observed deviations compared with the other machines, in terms of both total numbers per work shift (Figure 2) and per work cycle (Table 3 ). There were also smaller between-operator differences in frequencies of deviations during cutter work. For all machines, the principal kind of deviation was due to external disturbances (Table 3), in which chunks jamming the conveyor system and malfunctioning of the splitting axe were the most common. Human disturbances only constituted a relatively small proportion $(\leq 13 \%)$ of the observed deviations. The largest 
remaining proportion was caused by external factors (machine or wood), with no significant betweentreatment differences (Table 4).

\subsection{Perceived levels of deviations and work efficiency}

There were significant between-operator differences in perceived levels of deviation during work shifts (full ANOVA, $\mathrm{p}=0.014$ ), but there were no significant effects of machine, wood class or any of the pairwise interactions of the three factors on their perceived levels (full ANOVA, $\mathrm{p} \geq 0.127$ ). With the truncated ANOVA the results were similar, with a significant effect for operator $(\mathrm{p}<0.001)$ but not for machine, wood class or interaction between machine and wood class $(\mathrm{p} \geq 0.304)$. The results are presented in Table 5, in which the large standard deviations relate to differences in perceived deviation levels between operators, and the similarity in mean values between machines and wood classes are related to the lack of treatment effects.

As shown in Table 5, the relationships between the operators' perceptions of work efficiency and the tested variables were similar to the relationships with their perceived deviation levels, with a significant effect of operator (full ANOVA, $\mathrm{p}=0.053$, truncated ANOVA, $\mathrm{p}<0.001$ ), but no significant effects of machine, wood class or the pairwise machine and wood interaction (full ANOVA, $p \geq 0.119$; truncated ANOVA, $\mathrm{p} \geq 0.095$ ).

The most common reason for work interruptions reported by the operators was conveyor belt malfunction (Table 6), which resulted in operators stopping their normal work procedures to re-arrange the chunks or billets in the conveyor's intake to allow them to be transported away. Conveyor malfunctions did not occur as often for the wood processor, which in contrast to the other machines had a fixed fit with the conveyor. Instead, in more than half of the processor work shifts, operators reported that work was interrupted by chunks that landed awkwardly in the splitting department and needed to be adjusted before splitting (Table 6). Interruptions due to failure of the splitting process and split billets getting stuck under the splitting axe were also commonly reported. In total, interruption reports were least frequent for the cutter and most frequent for the processor. If conveyor-related malfunctions were excluded from the analysis, the difference was even more distinct. No interruptions were reported by operators after three (equivalent to $4.2 \%$ ) of the work shifts and four reports (5.6\%) addressed deviations of such character that they not were included in the observers' list. In addition, two operators' reports appeared to contradict the observers' categorisation, since deviations were reported as human disturbances that would have been recorded by observers as external disturbances.

Two operators suggested possible changes to the splitter machine and splitter work practices that would have contravened safety standards. The suggested change was to free one hand from the splitter's two-handed control, so that chunks could be loaded more rapidly. One operator suggested this after work with both wood classes and the other after work with Wood Class 2. It was noted that the former operator scored many deviations in relation to performed work cycles $(0.65$ and 0.54 deviations per splitter work cycle with Wood Classes 1 and 2, respectively, cf. Table 3), but neither of the two operators differed from the other operators in their perception of splitter deviation levels $(7-25 \mathrm{cM}$, cf. Table 5).

\subsection{Relationship between observed and perceived deviations}

No significant effect of wood class was detected in the ANOVAs, so it was not considered in further analysis of the relationship between perceived deviation levels and observed deviations which consequently focused on the effects of operator and machine. There were significant correlations between perceived levels of deviations and observed deviations per work cycle with the cutter $(p=0.003)$, but not for either of the other machines $(\mathrm{p} \geq 0.155)$ (Figure 3). Similarly, there was a significant positive correlation between perceived levels of deviations and the total number of deviations per work shift for cutter $\left(p=0.006, r^{2}=0.293\right)$, but not for either of the other machines ( $\mathrm{p} \geq 0.227)$.

In addition, perceptions of machine work efficiency were found to be inversely correlated to perceived deviation levels for work with the splitter and cutter $\left(\mathrm{p} \leq 0.007, \mathrm{r}^{2} \leq 0.399\right)$, but not the processor $(p=0.130)$. For the processor, the perceived efficiency was instead inversely related to observed deviations per work cycle $\left(\mathrm{p}=0.000, \mathrm{r}^{2}=0.203\right)$, which was not the case for either the cutter or splitter $(\mathrm{p} \leq 0.354)$. For the cutter, the perceived deviation levels were significantly and positively correlated with operators' allocation of external causes of perceived deviations $\left(\mathrm{p}=0.030, \mathrm{r}^{2}=0.197\right)$, but not for the splitter or processor $(\mathrm{p}=0.13$ and $\mathrm{p}=0.79$, respectively).

A larger proportion of observed deviations during cutter work were recorded as external disturbances, which generally tallied better with the operators' allocation of causes for perceived deviations than when the other machines were used (Figure 4). Conversely, in cases when low proportions of external disturbances occurred, there was less accordance between observed and perceived causes of devia- 
tions. However, substantial between-operator differences were found: a near-perfect correlation between observed and perceived deviation causes was found for one operator $\left(n=6, p=0.001, r^{2}=0.948\right)$, while there were positive (for all but one operator), but non-significant, correlations for all of the other operators $(\mathrm{p} \geq 0.267)$.

\section{Discussion}

\subsection{Results}

Observed deviations per unit time were found to be positively correlated to the number of work cycles performed for work with the cutter, but inversely related for work with the splitter and the processor (Figure 2). These findings imply that less time was required to correct deviations when using the cutter than when using the other machines. Moreover, fewer deviations were noted in cutter work, both for given time periods and per work cycle. Together, the findings indicate that for cutter-based production, an increased work rate results in a greater number of deviations. For splitter and processorbased production, however, deviations appear to be a limiting factor with regard to work rate, and their avoidance enables the work rate to rise. These findings are consistent with expectations in the sense that the cutting process involves the least complicated work (cf. Table 1) with the shortest time per work cycle and the fewest expected types of deviation (Table 2). Those factors were also reflected in the surprising consistency between operators in terms of deviations per work cycle during cutter work (Table 3). In this simple, routine type of work, even small changes in observed deviations were found to have a significant impact on operators' perceptions of deviation levels (Figure 3). The work with the splitter and processor machines was generally more complex, as manifested in the greater variation in observed and perceived deviation levels between different operators (Figure 3 ). The findings indicate that in more complex work situations observers' and operators' perceptions of deviations are not as easily matched. Furthermore, perceptions of deviations have been found to be generally stronger in relatively straightforward work, which has been argued to be related to the intrinsically lower level of coping options in such work, compared to more complex work (Zohar 1999).

The expected inverse relationship between perceptions of work efficiency and perception of deviation was not found for work with the processor, possibly because it was the least familiar type of machine, and known to be more efficient than cutters and splitters. Both of these factors may have caused disproportionally high proportions of deviations to have been perceived by the operators as being due to their own handling flaws rather than external deviations, in a similar manner to Fundamental Attribution Errors, as proposed by Sabini et al. (2001). Such indications are presented in Table 4 and Figure 4, but were not statistically significant. More difficult to explain was the correlation between the perceived efficiency of work with the processor and observed deviations per work cycle, which was not found for either other machine.

No significant differences in either observed or perceived deviations and efficiency were associated with the two wood classes, despite their differences in log diameter homogeneity, which was expected to generate different levels of deviations. Hence, it can be concluded that, for the wood classes used, individual operators influenced the three variables substantially more than the logs' physical characteristics.

\subsection{Definition of deviations}

A new piece of equipment is likely to be evaluated based on expectations and comparison to equipment it is replacing (c.f. Klein et al. 2005). Consequently, high observed levels of deviations could be perceived as low if preceding equipment had serious flaws - or vice versa. Despite the likely differences in experience and prejudices between operators, the hypothesised relationship between operators' perceptions and the occurrence of deviations was found in this experimental setting. This suggests that the focus has been on relevant deviations. However, it is less clear whether or not observed and perceived deviations would also be correlated during operators' normal work at home. Some actions initially perceived as deviations with the new piece of machinery would soon probably be anticipated, and considered to be normal rather than deviant, while others might require longer times for the operator to accept and expect. If so, there may be both relative and temporal dimensions to the deviation concept. Moreover, given the importance of the goal function mentioned in the introductory section, contextual elements should also be considered, since the operators' goals might have been different during the study than during work at home.

Due to the deviation concept being based on a relationship to a normative process (Kjellén 1984), the definition of deviations intrinsically implies a certain level of arbitrariness. In this study, most deviations perceived by the operators were also considered to be deviations by the observers (as listed in Table 2). However, even for commonly defined deviations, there was some discrepancy regarding the causes of deviations. For example, on two occa- 
sions operators reported a deviation type as being caused by human factors (i.e. himself), while the deviation type was recorded by the observer as being due to external factors, i.e. the machine or the wood (Table 6). Four deviation types reported by operators were not noted as expected deviations. Two of these cases were related to machine design and two to the operator's mental mode, all of which would be difficult to include in observatory studies of deviations from normative work, regardless of definitions. The mismatch might be explained by the fact that the observed number of deviations was related to a desired outcome, while operators were more likely to perceive deviations in relation to what they observed and what they expected (Klein et al. 2005). Despite these discrepancies, the structured list of observable deviations (Table 2) covered perceived deviations to a greater extent than expected. However, the utility of structured identification techniques is not obvious when analysing relations between observed and perceived deviations, since such techniques have been proven to both correctly predict more errors, but also raise more false alarms than unstructured assessments (Stanton and Stevenage 1998). Consequently, this study's aim to ensure the inclusion of all possible different types of deviations most likely resulted in a more extensive definition than the concept used by the operators when attempting to record work deviations. Although the assessment of deviations in an experimental setting for a relatively simple HME system, combined with the accordance between observed and perceived deviation types, supports the belief that the methodology applied here was acceptable, the study would probably have benefited from incorporating more detailed techniques for the assessment of deviations.

According to the definitions used in this study, some deviations were not recorded if they were not corrected by the operator, generally when billets were produced that did not meet target specifications (i.e. not re-splitting large diameter billets). This was, however, a deviation that increased work efficiency at the expense of output quality. Thus, it is unlikely that the inclusion of uncorrected deviations would have significantly affected the results. A further limitation of the study's design was the use of two observers. There were two reasons for this. Firstly, two observers were required to undertake the study within the available timeframe and, secondly, the observers were also assigned to specific operators with a further study objective in mind (i.e. Lindroos 2008). However, the observers recorded deviations similarly. Hence, the effects of using two observers were minimized and the measures taken (e.g. use of a structured deviation list, calibration exercises undertaken and interviews with operators) were considered sufficient to ensure the reliability of the study.

The study only addressed skill-based errors and actively excluded error types including problemsolving (c.f. Rasmussen 1983; Reason 1990). This limitation was imposed to focus attention on expected (yet unwanted) deviations, and ethical concerns (i.e. operator's safety). Under normal work situations deviations including problem-solving errors would, however, be highly relevant for the perception of production deviations which might influence behaviour.

Deviations from normal cutter work were both perceived and observed to be caused to a very limited extent by the operator, and the perceived and observed reports were more congruent than for splitter and processor work (Figure 4). Despite the limitations of possible mismatches between observed deviation rates and perceived deviation levels, this indicates that the less frequently deviations were caused by the operators, the more likely they were to assign deviations to similar causes as the observers. These results imply that finding accordance between perceptions and observations may not be straightforward. If the results are interpreted as meaning that operators differ greatly in terms of recognising when they cause deviations, then this will obstruct the process of drawing generalisations between perceptions and observations. On the other hand, if the results reflect more interactions with more complex HME system (Karwowski 1991), then attributing errors in an external-human dichotomy with any certainty may be very difficult. The latter interpretation bears resemblance to the concept of Fundamental Attribution Errors (Sabini et al. 2001), which is particularly relevant to this observer-operator context. Despite the difficulties implied with the interpretations, these issues are important challenges to confront in future studies of production deviation.

\subsection{Production deviations and risky behaviour}

Even though this experimental study did not focus on the relationship between operators' perceptions of deviations and how they might influence risky behaviour, some examples of such relationships were observed. During the study, for example, deviations were observed that resulted in violations of safety regulations, which were corrected by the observing researcher. In relation to processor-based work, the observed deviation of 'wrongly landing chunks' was highly likely to induce risky behaviour, in the form of operators attempting to correct the position of the wood chunks in the splitting compartment by reaching through the narrow operating 
area near the saw blade. The safe procedure was to intervene, if necessary, from the shielded far end of the splitting compartment, which involved the operator moving a couple of steps alongside the machine. In a few instances, the attempted correction coincided with an omission to return the log cradle, leaving the running saw blade exposed when the operator reached in front of it. Observers immediately corrected this violation, and no accidents occurred during the study. In a formal analysis of such an incident, the described characteristics would most likely have been classified as due to human error, despite the fact that the underlying cause was defective machine performance. These observations are considered to strengthen the hypothesis that production deviations can influence safety through triggering risky behaviour which may result in the violation of safe working practices. To eliminate this risk, the machine should be re-designed to improve the accuracy of chunks landing in the splitting compartment and to preclude the possibility of leaving the saw blade exposed.

\subsection{Practical uses}

During cutter work deviations occurred for all operators at a similar rate and the perception of deviations from cutter work correlated well with observed deviations between operators. Consequently, when analysing perceived deviations it should be possible to determine a threshold above which changes in behaviour are likely to occur that might result in safety violations. On the same basis it should be theoretically possible to establish levels of observed deviations that do not provoke changes, i.e. safe working levels. The relationship between actual and perceived deviations is unlikely to be linear, but rather to follow an accelerated power function, akin to many relationships between sensory perceptions and physical stimuli (Borg 1962, 1998). This means that the level of perceived deviations will not be significantly affected by small changes in observed deviations, but beyond a certain threshold even small increments will result in large changes to perceived deviations (Figure 5). This concept is consistent with the theory that the problem detection processes mainly contains the accumulation of discrepancies between what is observed and what is desired (Cowan 1986). However, more recent theories emphasise that cues to problems may also be subtle and dependent on both the context in which they arise and the experience of individuals dealing with them (Klein et al. 2005). Such problem detection theory fits with the lack of correlations between observed and perceived deviations for splitter and processor work, and the occurrence of perceived types of deviations that were not covered by the structured assessment (Table 2). Moreover, the modification of safety standards proposed by two operators in the study would fall outside such a deviation threshold limit, since it signified a desire to meet a specific work efficiency target (i.e. using a more efficient work method) and was thus beyond the remit of this study. Hence, the discrepancy between observed and expected work efficiency rates was for the operators the cue for behavioural changes that led to the desire to violate safe working practice, although they might not themselves have perceived a high level of deviations in the study. Therefore, a threshold level of work efficiency is probably needed to address the many hand accidents that occur in firewood processing, largely due to the deliberate or unconscious by-passing of safety standards (Lindroos et al. 2008). Consequently, it appears to be important to evaluate both the production deviations as well as work efficiency deviations (i.e. different deviation modes). In the same context, it might also be worthwhile to further investigate the deviations relating to different kinds of outputs. Work cycles proved to be a successful basis for analysis in this study, but more product-related assessment may be more relevant in other settings. In forestry production research published by Lindroos (2008) observed deviations were generally related to the volume of produced firewood $\left(\mathrm{m}^{3}\right)$. However, to convert the amount of produced billets to volume $\left(\mathrm{m}^{3}\right)$ during the work is a rather abstract operation, and was not therefore considered useful when relating observed ratios of deviations with the operators' perceived levels of deviations.

The difficulties of setting threshold levels are compounded by the considerable differences between operators. In order to establish safe production threshold levels, sound information on deviations is needed. Such deviations are indisputably subject to great challenges in terms of individual differences due, inter alia, to variations in age, gender, culture and previous experience. However, this is also true for threshold levels applied to individuals in other contexts, e.g. exposure to potentially hazardous substances, and age and safe drinking limits for driving cars. Moreover, the challenge is likely to increase substantially if applied to larger HME systems, which have been argued to be inherently incompatible (Karwowski 1991). Nevertheless, within the given bounds of plausibility, the concept of deviation and work efficiency thresholds merit further research.

\section{Conclusions and further research}

This study presents new data and information on production-related deviations from normative work 
procedures in a highly repetitive and self-paced activity. It also provides evidence of a relationship between observed and perceived levels of deviation, and indications that the difficulty in matching observed and perceived levels of deviation increases as the complexity of the normative work increases. The use of production deviations as indicators of poor work efficiency, and thus as triggers for influencing risky behaviour, might prove to be useful in the prevention of future accidents at work. In this context, the production deviation concept could play an important role in efforts to merge usability and safety research into a more holistic approach for assessing the performance of HME systems. Further, if different types of deviation are considered, the concept might become even more useful. However, in order to evaluate the potential value of further research into production deviations, in terms of e.g. establishing safety thresholds, the relationship between workers' perceptions of production deviations and changes to risky behaviour requires further investigation.

\section{Acknowledgement}

This study was conducted within the FORprogramme, which addresses the working conditions of self-employed family forestry. The work was financially supported by the Faculty of Forest Sciences of the Swedish University of Agricultural Sciences, the SLO foundation's grant SLO-892, and Baltic forest - an Interreg 3B project. Lennartfors $\mathrm{AB}$ and Norra Skogsägarna kindly provided testing material. Thomas Hörnlund, Urban Johansson, Tony Knif, Christer Hedegård and the Regional Forestry Board of Västerbotten are thanked for their help in undertaking the field work. Pär Lindroos is especially thanked for invaluable assistance in the field study. Thanks are also due to Carola Häggström, Gregory Neely, Dianne Staal Wästerlund and Stefan Söderfjell for valuable comments and to SeesEditing Ltd. for revising the English.

\section{References}

Baber, C. and Stanton, N. A., 1994. Task analysis for error identification: a methodology for designing error-tolerant consumer products. Ergonomics 37:11, 1923-1941.

Baber, C. and Stanton, N. A., 1996. Human error identification techniques applied to public technology: predictions compared with observed use. Applied Ergonomics 27:2, 119-131.

Battmann, W. and Klumb, P., 1993. Behavioural economics and compliance with safety regulations. Safety Science 16:1, 35-46.
Borg, E. and Borg, G., 2002. A comparison of AME and CR100 for scaling perceived exertion. Acta Psychologica 109:2, 157-175.

Borg, G., 1962. Physical performance and perceived exertion. Studia Psychologica et Paedagogica, Series altera, Investigationes XI. Lund University, Sweden.

Borg, G., 1998. Borg's perceived exertion and pain scales. Human Kinetics. Champaign, Illinois, U.S.A.

Carlsson, P., 2003. Att brinna för ved [To burn for firewood]. Bachelor thesis. Department of culture and media, Umeå university. Umeå.

Chernev, A., 2004. Goal-attribute compatibility in consumer choice. Journal of Consumer Psychology 14:1-2, 141-150.

Cowan, D. A., 1986. Developing a Process Model of Problem Recognition. The Academy of Management Review 11:4, 763-776.

Dekker, S. W. A., 2002. Reconstructing human contributions to accidents: the new view on error and performance. Journal of Safety Research $33: 3,371-385$.

Elvik, R., 2006. Laws of accident causation. Accident Analysis \& Prevention 38:4, 742-747.

European Committee for Standardization, 1999. EN 609-2 Agricultural and forestry machinery Safety of splitters - Part 2: Screw splitters. Brussels, Belgium.

European Committee for Standardization, 2002. EN 1870-6 Safety of wood working machines - Circular sawing machines - Part 6: Firewood sawing machine/circular bench with manual loading and/or unloading. Brussels, Belgium.

European Committee for Standardization, 2003. EN 609-1 Agricultural and forestry machinery Safety of splitters - Part 1: Wedge splitters. Brussels, Belgium.

European Committee for Standardization, 2004. EN ISO 11681-1 Machinery for forestry - Portable chain-saw safety requirements and testing - Part 1: Chain-saws for forest service. Brussels, Belgium.

Gibson, J. J., 1986. The Ecological Approach to Visual Perception. Lawrence Erlbaum Associates. Hillsdale, N.J.

Gielo-Perczak, K. and Karwowski, W., 2003. Ecological models of human performance based on affordance, emotion and intuition. Ergonomics $46: 1,310-326$.

Hale, A. R. and Glendon, A. I., 1987. Individual behaviour in the control of danger. Elsevier Science Publisher B.V. Amsterdam.

Hale, A. R., Heming, B. H. J., Carthey, J. and Kirwan, B., 1997. Modelling of safety management systems. Safety Science 26:1-2, 121-140.

Harms-Ringdahl, L., 2009. Analysis of safety functions and barriers in accidents. Safety Science 47:3, 353-363.

Heider, F., 1958. The psychology of interpersonal relations. John Willey \& Sons, Inc. New York, N.Y. 
Higgins, E. T., 1997. Beyond Pleasure and Pain. American Psychologist 52:12, 1280-1300.

Higgins, E. T., 2000. Making a good decision: Value from fit. American Psychologist 55:11, 1217-1230.

Hollnagel, E., 2004. Barriers and accident prevention. Ashgate Publishing Company. Hampshire, England.

Johnson, W. G., 1975. MORT: The Management Oversight and Risk Tree. Journal of Safety Research 7:1, 4-15.

Kaplan, S., 1983. A Model of Person-Environment Compatibility. Environment and Behavior 15:3, 311-332.

Karwowski, W., 1991. Complexity, fuzziness, and ergonomic incompatibility issues in the control of dynamic work environments. Ergonomics $34: 6,671-686$

Kjellén, U., 1984. The deviation concept in occupational accident control. Part I: Definition and classification; Part II: Data collection and assessment of significance. Accident Analysis and Prevention 16:4, 289-323.

Kjellén, U. and Hovden, J., 1993. Reducing risks by deviation control--a retrospection into a research strategy. Safety Science 16:3-4, 417-438.

Klein, G., Pliske, R., Crandall, B. and Woods, D. D., 2005. Problem detection. Cognition, Technology \& Work 7:1, 14-28.

Lawton, R., 1998. Not working to rule: Understanding procedural violations at work. Safety Science 28:2, 77-95.

Lindroos, O., Lidestav, G. and Nordfjell, T., 2005. Swedish non-industrial private forest owners self-employment and equipment investments. Small-Scale Forest Economics, Management and Policy 4:4, 409-426.

Lindroos, O., 2008. The effects of increased mechanization on time consumption in small-scale firewood processing. Silva Fennica 42:5, 791805.

Lindroos, O., Wilhelmson Aspman, E., Lidestav, G. and Neely, G., 2008. Accidents in family forestry's firewood production. Accident Analysis and Prevention 40:3, 877-886.

McClelland, I., 1998. Product assessment and user trial. In Wilson, J. R. and Corlett, E. N. (eds)
Evaluation of human work. Taylor \& Francis Ltd. London. pp 251-284.

Norman, D. A., 2002. The design of everyday things. Basic Books. New York.

Nuutinen, M., 2005. Contextual assessment of working practices in changing work. International Journal of Industrial Ergonomics 35:10, 905-930.

Perrow, C., 1984. Normal accidents: living with high-risk technology. Prentice-Hall. New Jersey, U.S.A.

Phipps, D. L., Parker, D., Pals, E. J. M., Meakin, G. H., Nsoedo, C. and Beatty, P. C. W., 2008. Identifying violation-provoking conditions in a healthcare setting. Ergonomics 51:11, 16251642.

Rasmussen, J., 1983. Skills, rules, knowledge; signals, signs and symbols and other distinctions in human performance models. SMC-13, IEEE Transactions: Systems, Man \& Cybernetics, pp 257-267.

Rasmussen, J., 1997. Risk management in a dynamic society: a modelling problem. Safety Science 27:2-3, 183-213.

Reason, J., 1990. Human error. Cambridge University Press. Cambridge, UK.

Reason, J., 1995. A systems approach to organisational error. Ergonomics 38:8, 1708-1721.

Sabini, J., Siepmann, M. and Stein, J., 2001. The really fundamental attribution error in social psychological research. Psychological Inquiry 12:1, $1-15$.

Simon, H., 1970. The sciences of the artificial. MIT Press. Cambridge, MA.

Stanton, N. A. and Stevenage, S. V., 1998. Learning to predict human error: issues of acceptability, reliability and validity. Ergonomics 41:11, 1737 1756.

Zar, J. H., 1999. Biostatistical analysis. PrenticeHall, Inc. Upper Saddler River, New Jersey, U.S.A.

Zohar, D., 1999. When things go wrong: The effect of daily work hassles on effort, exertion and negative mood. Journal of Occupational and Organizational Psychology 72, 265-283. 


\section{Tables and Figures}

Table 1. Normative work processes
Cutter
a) Load log on machine's log cradle.
Processor
b) Push cradle towards saw blade so a
a) Load log on machine's log cradle. chunk is cut off, then return cradle.
b) Push cradle towards saw blade so a chunk is cut off, then return cradle.
c) Feed $\log (30 \mathrm{~cm})$.
c) Actuate splitting.
d) Repeat from b) until the log's last chunk.
d) Feed $\log (30 \mathrm{~cm})$.
e) Put last chunk in conveyor intake.
f) Repeat from a).
e) When piston is automatically returned, repeat from b) until the log's last chunk.

\section{Splitter}
f) Put last chunk in splitting apartment and perform c).
a) Load chunk on machine's chunk holder. $\quad$ g) Repeat from a).
b) Actuate splitting.
c) Return piston and repeat from a).

Table 2. Expected deviations from normative work processes. Letters indicate the work element(s) according to the normative work processes in Table 1, during which the deviation was expected

\begin{tabular}{llll}
\hline Deviation category & Cutter & Splitter & Processor \\
\hline Re-cuts: large diameter logs & $\mathrm{b}$ & $\mathrm{b}$ \\
Re-splits & & $\mathrm{b}$ & $\mathrm{c}$ \\
\hline Large diameter chunks & - & $\mathrm{b}$ & $\mathrm{c}$ \\
Producing too fine billets & & $\mathrm{a}-\mathrm{b}$ & \\
External disturbances & & $\mathrm{b}$ \\
Cutting failure due to crook or blade pinch & $\mathrm{b}$ & - & $\mathrm{b}-\mathrm{d}$ \\
Long logs tipping up and rolling out of cradle after cutting & $\mathrm{b}-\mathrm{c}$ & - & $\mathrm{a}-\mathrm{b}, \mathrm{d}$ \\
Chunk length indicator moving & $\mathrm{a}-\mathrm{c}$ & - & $\mathrm{c}$ \\
Splitting failure due to insufficient piston force & - & $\mathrm{b}$ & $\mathrm{c}$ \\
Bad splitting due to climbing splitting axe or sliding chunk & - & $\mathrm{b}$ & $\mathrm{c}$ \\
Billets getting stuck under splitting axe & - & $\mathrm{b}$ & - \\
Billets falling from splitting table & - & $\mathrm{b}$ & $\mathrm{b}$ \\
Chunks landing wrongly in the splitting department & - & - & $\mathrm{c}$ \\
Conveyor not extracting properly & $\mathrm{c}, \mathrm{e}$ & $\mathrm{b}$ & \\
Human disturbances & & & $\mathrm{b}$ \\
Interrupting cutting before chunk is cut off & $\mathrm{b}$ & - & $\mathrm{b}$ \\
Cutting in the air (forgetting to feed log) & $\mathrm{b}-\mathrm{c}$ & - & $\mathrm{b}, \mathrm{d}$ \\
Unsuccessfully operating splitting actuators & - & $\mathrm{b}$ & $\mathrm{b}$ \\
Actuating splitting without chunk & - & $\mathrm{b}$ & $\mathrm{b}$ \\
Forgetting to return piston & - & $\mathrm{c}$ & - \\
Cutting a second chunk without splitting the first & - & - & $\mathrm{b}-\mathrm{c}$ \\
Cutting before piston was fully returned & - & - & $\mathrm{b}$ \\
Dropping log or chunk & $\mathrm{a}-\mathrm{f}$ & $\mathrm{a}-\mathrm{c}$ & $\mathrm{a}-\mathrm{g}$ \\
Sum of expected deviations in all categories & 8 & 11 & 18 \\
\hline
\end{tabular}
- = not applicable. 
Table 3. Number of work cycles and number of observed deviations as a ratio of work cycles per work shift (mean and $\mathrm{SD}, \mathrm{n}=12$

\begin{tabular}{|c|c|c|c|c|c|c|}
\hline \multirow[b]{3}{*}{ Machine } & \multirow{3}{*}{$\begin{array}{l}\text { Work cycles } \\
\text { (n / work shift) }\end{array}$} & \multicolumn{5}{|c|}{ Observed deviation rate (\% of work cycles) } \\
\hline & & \multicolumn{2}{|l|}{ Extra work } & \multicolumn{2}{|l|}{ Disturbances } & \multirow[b]{2}{*}{ Total } \\
\hline & & Re-cuts & Re-splits & External & Human & \\
\hline \multicolumn{7}{|c|}{ Wood class 1} \\
\hline Splitter & $411.8^{\mathrm{b}}(91.8)$ & $\begin{array}{l}0.2 \quad(0.3) \\
-\end{array}$ & $3.6^{\mathrm{ab}}(3.2)$ & $\begin{array}{l}0.3^{(3.0)} \\
30.1^{\mathrm{b}}(13.5)\end{array}$ & $\begin{array}{l}0.5^{\mathrm{ab}}(5.7) \\
3.5^{\mathrm{b}}(5.7)\end{array}$ & $\begin{array}{l}6.8^{\mathrm{c}}(2.9) \\
37.2^{\mathrm{b}}(18.5)\end{array}$ \\
\hline Processor & $478.8^{\mathrm{b}}(105.2)$ & $0.1^{\mathrm{a}}(0.3)$ & $1.1^{\mathrm{a}}(1.1)$ & $26.4^{\mathrm{b}}(19.4)$ & $3.6^{\mathrm{bc}}(2.4)$ & $31.3^{b}(19.7)$ \\
\hline \multicolumn{7}{|c|}{ Wood class 2} \\
\hline Cutter & $750.8^{\mathrm{c}}(157.4)$ & $0.2^{\mathrm{a}}(0.4)$ & - & $5.8^{\mathrm{a}}(2.9)$ & $0.3^{\mathrm{a}}(0.3)$ & $6.3^{\mathrm{a}}(3.2)$ \\
\hline Splitter & $415.8^{\mathrm{b}}(92.5)$ & - & $10.1^{b}(6.5)$ & $21.4^{\mathrm{b}}(9.59)$ & $2.6^{\mathrm{ab}}(2.7)$ & $32.1^{\mathrm{b}}(13.7)$ \\
\hline Processor & $527.6^{\text {ac }}(96.9)$ & $0.3^{\mathrm{a}}(0.5)$ & $9.5^{\mathrm{b}}(7.0)$ & $25.4^{\mathrm{b}}(17.8)$ & $3.8^{\mathrm{bc}}(2.3)$ & $39.1^{\mathrm{b}}(20.7)$ \\
\hline
\end{tabular}

- = not applicable. Within columns, different superscript letters indicate significant $(\mathrm{p}<0.05)$ differences

(Tukey HSD for work cycles and Dunnet's C for other columns).

Table 4. Proportion of observed externally caused deviations out of the observed number of deviations and the proportion of operators' perceived externally caused deviations out of the total level of perceived deviations, by machine and wood class $(\%$, missing shares to $100 \%$ constitutes deviations caused by human factors)

\begin{tabular}{|c|c|c|c|c|c|c|}
\hline \multirow[b]{2}{*}{ Machine } & \multicolumn{3}{|c|}{ Wood class 1} & \multicolumn{3}{|c|}{ Wood class 2} \\
\hline & Mean & SD & Interval & Mean & SD & Interval \\
\hline \multicolumn{7}{|c|}{ Observed deviations } \\
\hline Cutter & $94.1^{\mathrm{a}}$ & 7.9 & $72-100$ & $93.5^{\mathrm{a}}$ & 8.6 & $71-100$ \\
\hline Splitter & $92.1^{\mathrm{a}}$ & 7.8 & $73-99$ & $92.0^{\mathrm{a}}$ & 7.2 & $74-98$ \\
\hline Processor & $86.9^{\mathrm{a}}$ & 9.1 & $69-98$ & $89.3^{\mathrm{a}}$ & 7.0 & $80-99$ \\
\hline \multicolumn{7}{|c|}{ Perceived deviations } \\
\hline Cutter & $87.9^{\mathrm{a}}$ & 15.1 & $50-100$ & $80.4^{\mathrm{a}}$ & 18.4 & $50-100$ \\
\hline Splitter & $79.1^{\mathrm{a}}$ & 20.8 & $30-100$ & $82.7^{\mathrm{a}}$ & 15.4 & $50-100$ \\
\hline Processor & $69.6^{\mathrm{a}}$ & 16.6 & $40-95$ & $68.3^{\mathrm{a}}$ & 27.5 & $0-95$ \\
\hline
\end{tabular}

Within observed and perceived deviations, different superscript letters indicate significant $(\mathrm{p}<0.05)$

differences (Tukey HSD with arcsine transformation of proportions).

Table 5. Perceived levels of deviations and work efficiency per work shift by machine and wood class (unit $\mathrm{cM}$ on the Borg CR100-scale)

\begin{tabular}{|c|c|c|c|c|c|c|}
\hline \multirow[b]{2}{*}{ Machine } & \multicolumn{3}{|c|}{ Wood class 1} & \multicolumn{3}{|c|}{ Wood class 2} \\
\hline & Mean & SD & Interval & Mean & $\mathrm{SD}$ & Interval \\
\hline \multicolumn{7}{|l|}{ Deviations } \\
\hline Cutter & $24.3^{\mathrm{a}}$ & 17.4 & $2-55$ & $20.9^{\mathrm{a}}$ & 13.8 & $2-45$ \\
\hline Splitter & $28.5^{\mathrm{a}}$ & 21.8 & $2-70$ & $27.4^{\mathrm{a}}$ & 16.5 & $2-60$ \\
\hline Processor & $28.8^{\mathrm{a}}$ & 17.5 & $3-65$ & $25.5^{\mathrm{a}}$ & 14.5 & $8-55$ \\
\hline \multicolumn{7}{|c|}{ Work efficiency } \\
\hline Cutter & $40.0^{\mathrm{a}}$ & 18.5 & $20-75$ & $52.8^{\mathrm{a}}$ & 20.5 & $23-90$ \\
\hline Splitter & $55.4^{\mathrm{a}}$ & 24.8 & $20-100$ & $52.9^{\mathrm{a}}$ & 18.0 & $30-90$ \\
\hline Processor & $52.5^{\mathrm{a}}$ & 16.9 & $25-70$ & $49.2^{\mathrm{a}}$ & 13.3 & $35-70$ \\
\hline
\end{tabular}

Within deviations and efficiency, different superscript letters indicate significant $(\mathrm{p}<0.05)$ differences (Tukey HSD). 
Table 6. Deviations reported by operators at the end of each work shift as a percentage of number of work shifts ( $\mathrm{n}=12$ per machine and wood class combination). More than one deviation type could be reported after each work shift. Deviation reports are sorted to correspond to deviation categories used by observers. Reported deviations that were not included in the observation study are sorted under "not categorised", while deviations that would have been noted under another category by observers are marked with superscript numbers. Total numbers of work shifts were 24,48 or 72 for deviations applicable to 1, 2 or 3 machines, respectively.

\begin{tabular}{|c|c|c|c|c|c|c|c|}
\hline \multirow[b]{2}{*}{ Deviation category } & \multicolumn{2}{|l|}{ Cutter } & \multicolumn{2}{|l|}{ Splitter } & \multicolumn{2}{|c|}{ Processor } & \multirow[b]{2}{*}{ Total } \\
\hline & $\begin{array}{c}\text { Wood } \\
1\end{array}$ & $\begin{array}{c}\text { Wood } \\
2\end{array}$ & $\begin{array}{c}\text { Wood } \\
1\end{array}$ & $\begin{array}{c}\text { Wood } \\
2\end{array}$ & $\begin{array}{c}\text { Wood } \\
1\end{array}$ & $\begin{array}{c}\text { Wood } \\
2\end{array}$ & \\
\hline$\underline{\text { Re-cuts: large, crocked logs }}$ & 0 & 8.3 & - & - & 0 & 0 & 2.1 \\
\hline$\underline{\text { Re-splits }}$ & - & - & 0 & 0 & 0 & 0 & 0 \\
\hline \multicolumn{8}{|l|}{ External disturbances } \\
\hline Conveyor not extracting properly & 83.3 & 91.7 & 75.0 & 83.3 & 41.7 & 33.3 & 68.1 \\
\hline $\begin{array}{l}\text { Chunks landed wrongly in the } \\
\text { splitting department }\end{array}$ & - & - & - & - & 50.0 & 75.0 & 62.5 \\
\hline $\mathrm{Bad} /$ failed splitting & - & - & 16.7 & 25.0 & 41.7 & 8.3 & 22.9 \\
\hline Billets stuck under splitting axe & - & - & 8.3 & 0 & 16.7 & 33.3 & 14.6 \\
\hline Billets fell from splitting table & - & - & 8.3 & 8.3 & - & - & 4.2 \\
\hline $\begin{array}{l}\text { Too short log cradle, log tipped up } \\
\text { after cutting }\end{array}$ & 8.3 & 0 & - & - & 8.3 & 0 & 4.2 \\
\hline Chunk length indicator moved & 0 & 8.3 & - & - & 0 & 0 & 2.1 \\
\hline $\begin{array}{l}\text { Blade cover did not return } \\
\text { properly }\end{array}$ & 0 & 8.3 & - & - & 0 & 0 & 2.1 \\
\hline Log turned and squeezed blade & 0 & 0 & - & - & 0 & 8.3 & 2.1 \\
\hline Sum external disturbances & 91.7 & 108.3 & 108.3 & 116.7 & 158.3 & 158.3 & 123.6 \\
\hline \multicolumn{8}{|l|}{ Human disturbances } \\
\hline Missed the splitting handle & - & - & - & - & 8.3 & 8.3 & 8.3 \\
\hline Forgot to return piston & - & - & 16.7 & 8.3 & 0 & 0 & 6.3 \\
\hline $\begin{array}{l}\text { Cutting before piston was } \\
\text { fully returned }\end{array}$ & - & - & - & - & 0 & 8.3 & 4.2 \\
\hline $\begin{array}{l}\text { Splitting failure due to bad } \\
\text { placement of chunk }{ }^{1)}\end{array}$ & - & - & 8.3 & 0 & - & - & 4.2 \\
\hline $\begin{array}{l}\text { Chunk landed wrong in the } \\
\text { splitting department due } \\
\text { to bad handling }{ }^{1)}\end{array}$ & - & - & - & - & 8.3 & 0 & 4.2 \\
\hline Sum human disturbances & 0 & 0 & 25.0 & 8.3 & 16.7 & 16.7 & 11.1 \\
\hline \multicolumn{8}{|l|}{ Not categorised } \\
\hline $\begin{array}{l}\text { Log cradle shape made log } \\
\text { feeding difficult }\end{array}$ & 0 & 8.3 & - & - & 0 & 0 & 2.1 \\
\hline Too long stroke length (wait time) & - & - & 0 & 0 & 8.3 & 0 & 2.1 \\
\hline Lack of concentration & 0 & 0 & 0 & 0 & 8.3 & 0 & 2.1 \\
\hline Lack of coordination & 0 & 0 & 0 & 0 & 8.3 & 0 & 2.1 \\
\hline Sum not categorised & 0 & 8.3 & 0 & 0 & 25.0 & 0 & 5.6 \\
\hline All deviation categories & 91.7 & 125.0 & 133.3 & 133.3 & 191.7 & 175.0 & 141.7 \\
\hline No deviation reported & 0 & 8.3 & 8.3 & 8.3 & 0 & 0 & 4.2 \\
\hline
\end{tabular}
- = not applicable; ${ }^{1)}$ would have been noted as an external disturbance by observers. 


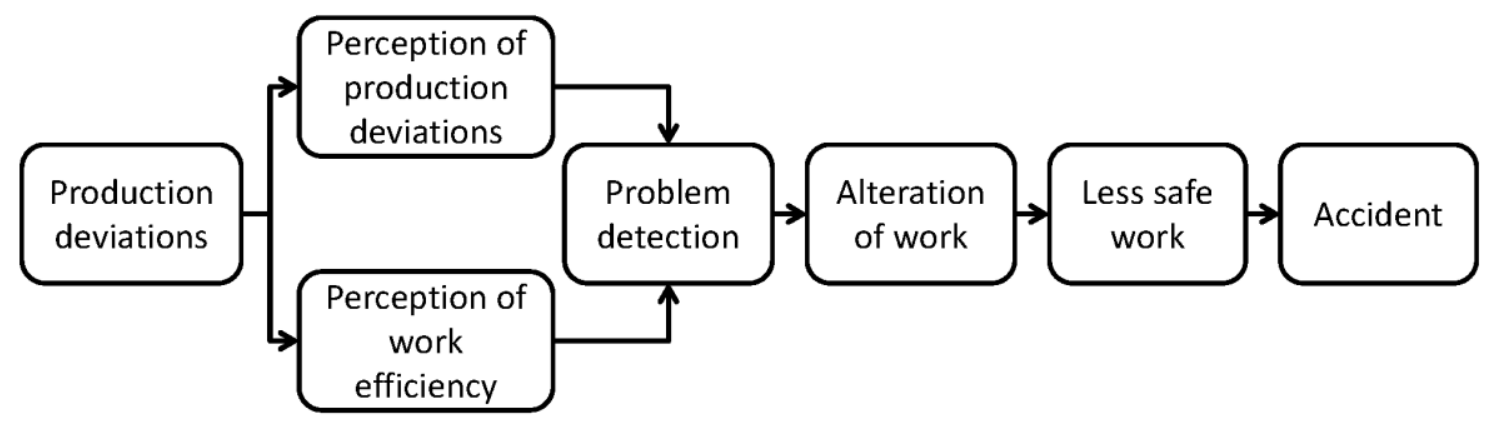

Figure 1. Flow chart of ways in which production deviations may indirectly result in accidents. It should be noted that other paths may be followed, e.g. a production deviation may lead to a total shutdown of a process, or an alteration of work could lead to the initiation of safer procedures, but here, as in the paper, the focus is on the link between deviations and possible accidents.

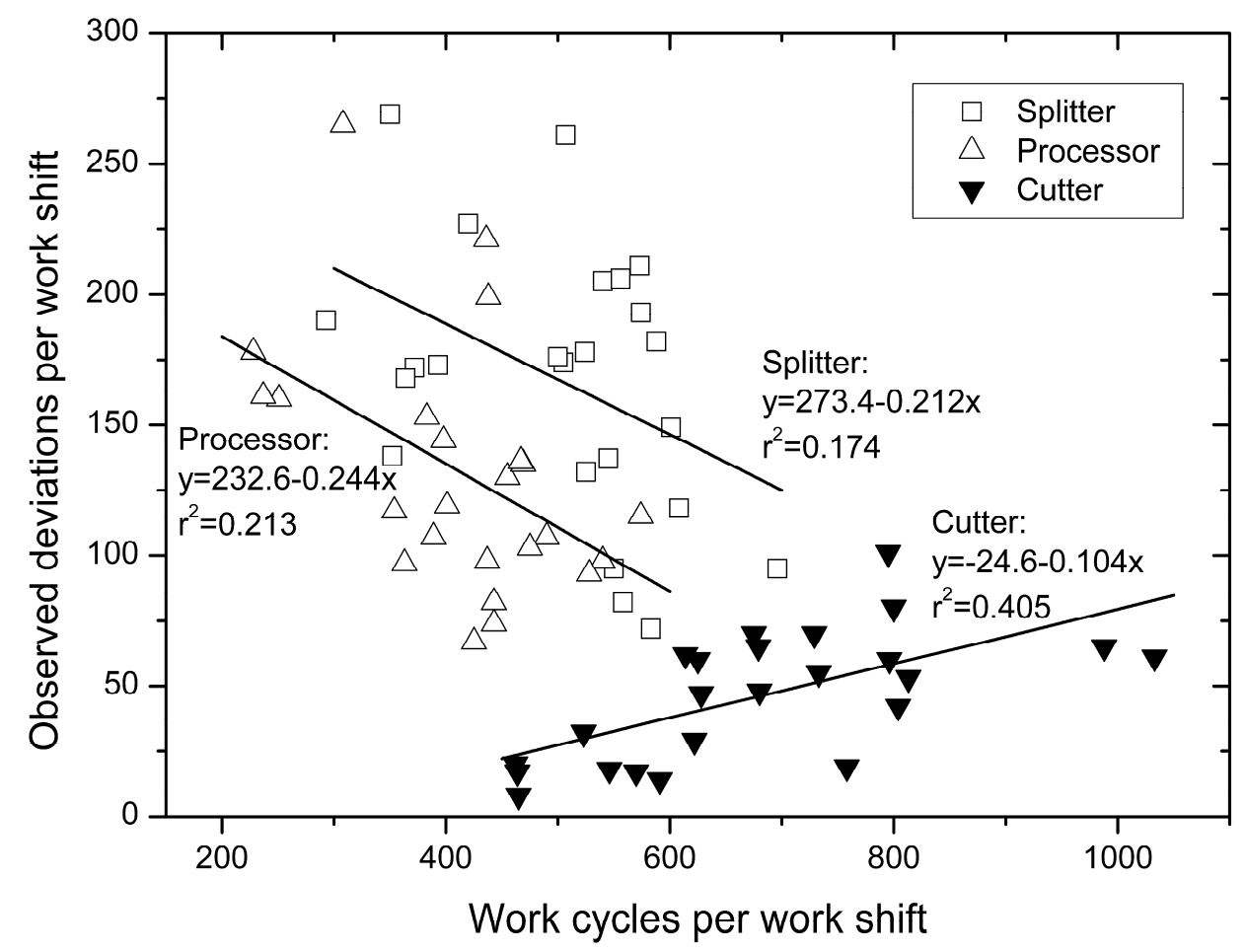

Figure 2. Relationship between number of work cycles and observed number of deviations per work shift. Note: two observations per operator and machine. 


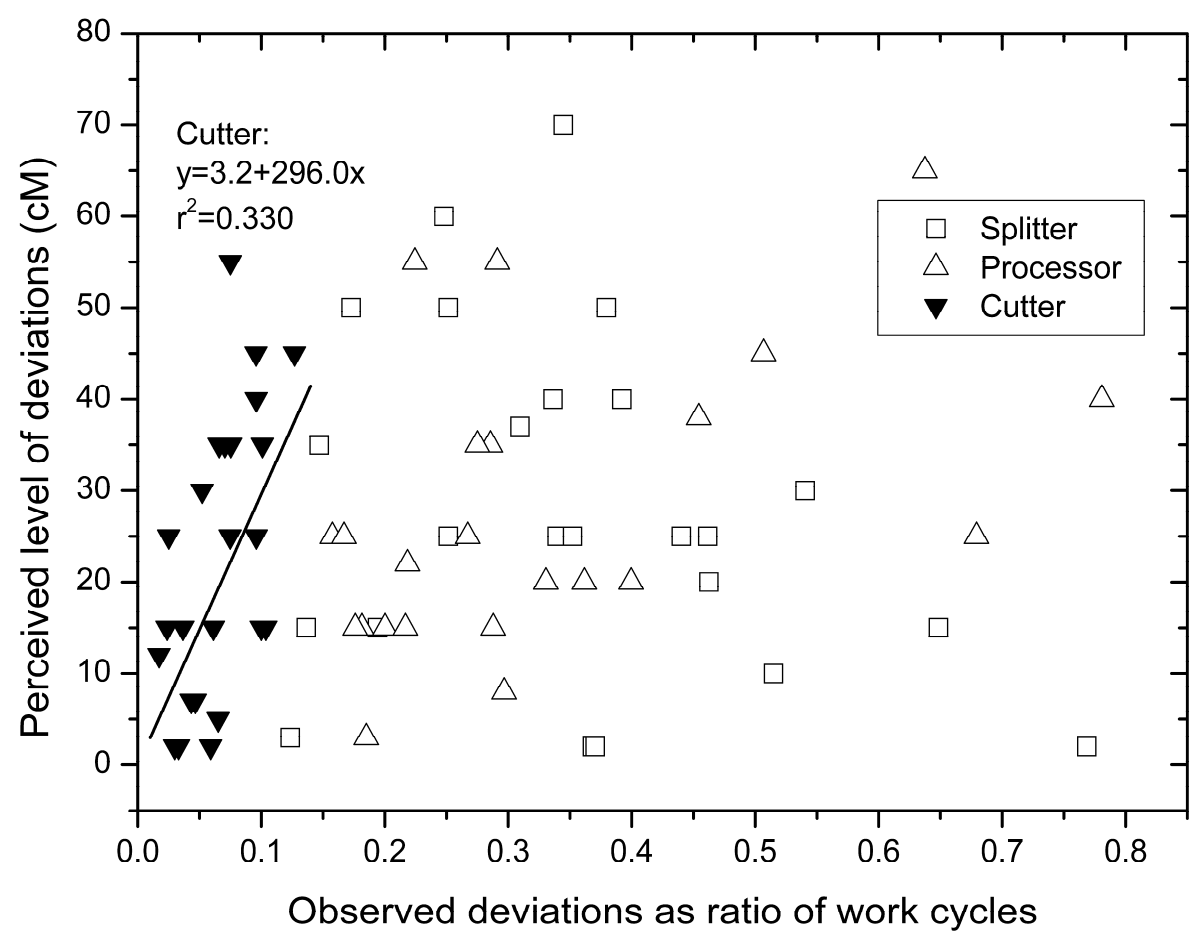

Figure 3. Relationship between perceived and observed deviations per work cycle. Note: two observations per operator and machine.

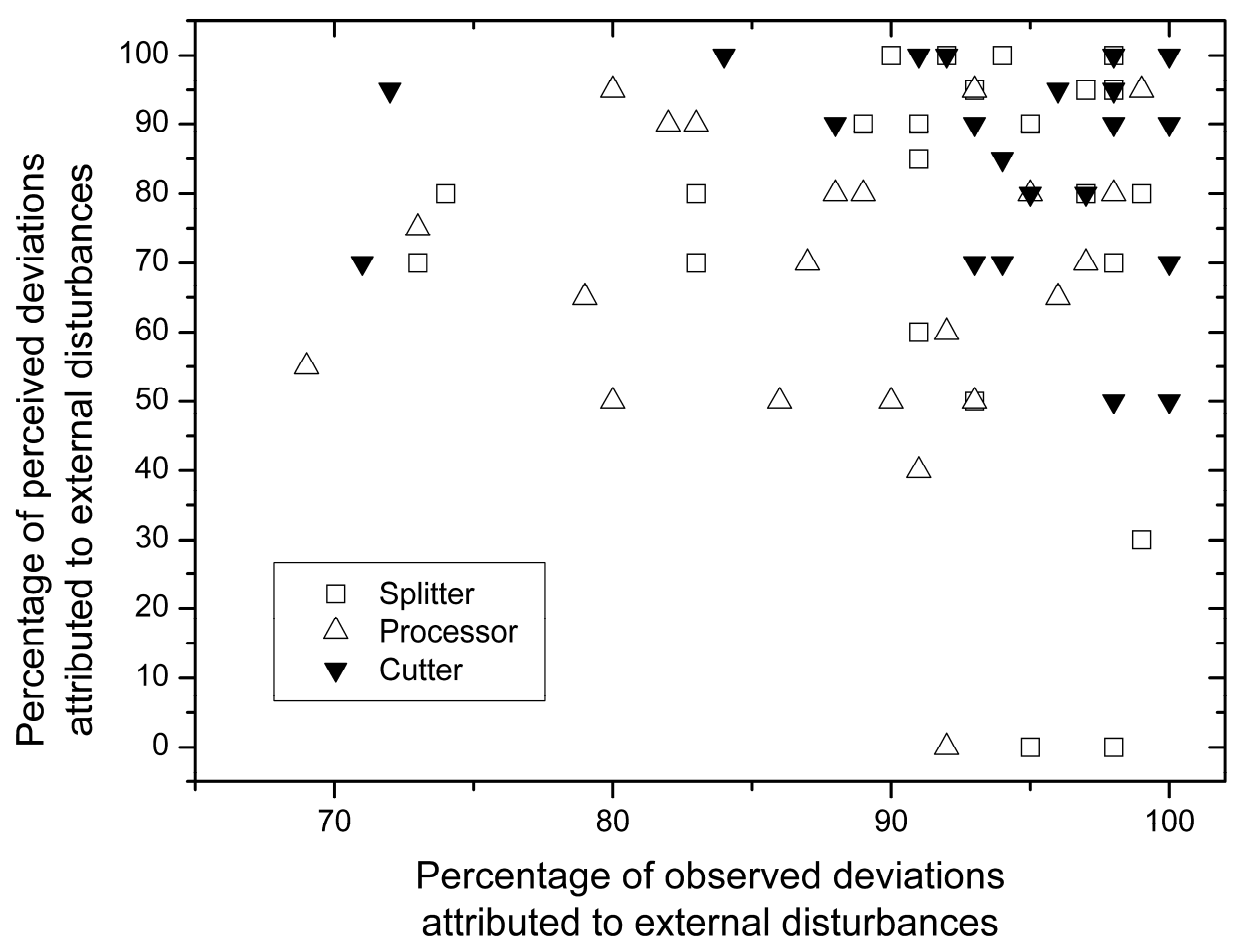

Figure 4. Relationship between perceived and observed external causes of deviations. Note: two observations per operator and machine. 


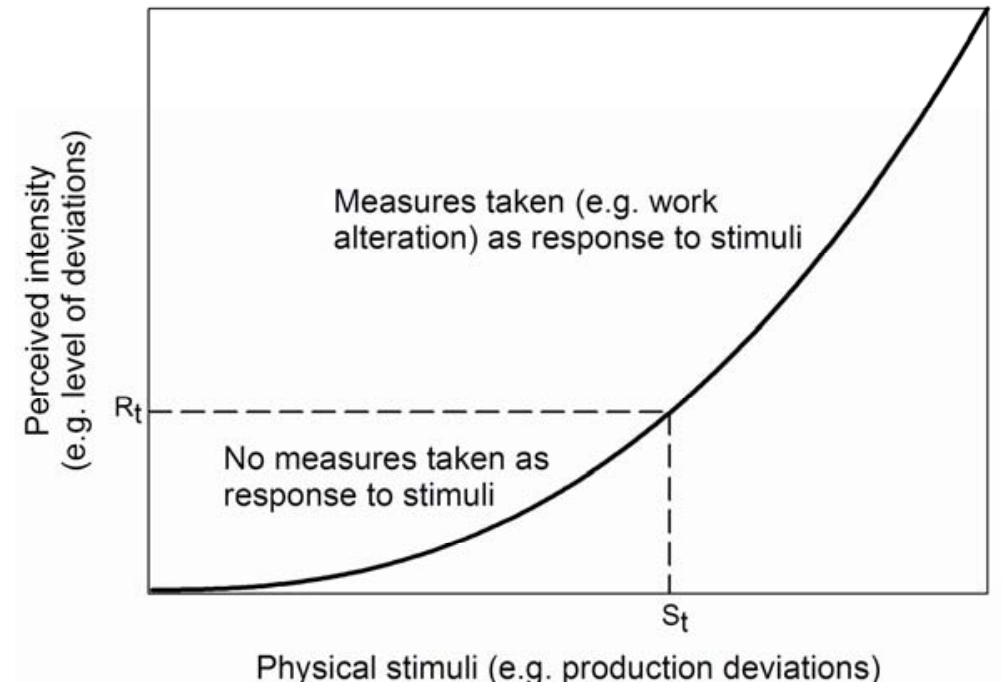

Figure 5. Positively accelerating relationship between physical stimuli and the level of perceived intensity (response). $\mathrm{R}_{\mathrm{t}}$ indicates a stipulated threshold level for the perceived intensity above which measures will be taken to interact with the stimuli (e.g. decrease deviations by work alterations). $S_{t}$ is the physical stimuli level that corresponds to $\mathrm{R}_{\mathrm{t}}$. 